\title{
A 3D Cu-phosphonate metal-organic framework with Cu-coordina- tion-enhanced electrical conductivity
}

\author{
Craig A. Peeples ${ }^{\mathrm{a}}$, Ahmet Çetinkaya ${ }^{\mathrm{b}}$, Franz-Josef Schmitt ${ }^{\mathrm{c}}$, Patrik Tholen ${ }^{\mathrm{d}}$, Yunus Zorlu ${ }^{\mathrm{e}}$, Kai Bin Yu ${ }^{\mathrm{f}}$, \\ Ozgur Yazaydin ${ }^{\mathrm{f}}$, Jens Beckmann" ${ }^{\mathrm{g} *}$, Gabriel Hanna ${ }^{\mathrm{a} *}$, Gündoğ Yücesan ${ }^{\mathrm{d} *}$ \\ ${ }^{a}$ University of Alberta, 116 St. and 85 Ave. Edmonton, Alberta, Canada T6G 2R3 \\ ${ }^{b}$ Department of Bioengineering, Yildiz Technical University, Esenler, Istanbul, \\ Turkey \\ 'Martin-Luther-Universität Halle-Wittenberg, 06120, Halle (Saale), Germany \\ ${ }^{\mathrm{d}}$ Technische Universität Berlin, Gustav-Meyer-Allee 25, 13355 Berlin, Germany \\ ${ }^{e}$ Gebze Technical University, Department of Chemistry, 41400 Gebze-Kocaeli, Turkey \\ fUniversity College London, Torrington Place, London WC1E 7JE, United Kingdom \\ ${ }^{\mathrm{g}}$ Universität Bremen, Leobener Str. 7, 28359 Bremen, Germany
}

*Correspondence to: yuecesan@tu-berlin.de, gabriel.hanna@ualberta.ca, j.beckmann@uni-bremen.de,

KEYWORDS: conductive MOFs, supercapacitors, BET surface area, MOF design and synthesis

\begin{abstract}
Herein, we report on the synthesis and electronic properties of the phosphonate metal-organic framework (MOF) $\mathrm{Cu}_{3}\left(\mathrm{H}_{5}-\mathrm{MTPPA}\right)_{2}\left(\mathrm{H}_{8}-\mathrm{MTPPA}=\right.$ methane tetra- $p$-phenylphosphonic acid). This MOF, termed TUB1, has a unique one-dimensional inorganic building unit composed of square planar and distorted trigonal bipyramidal copper atoms, and a calculated BET surface area of $766.2 \mathrm{~m}^{2} / \mathrm{g}$. The formation of TUB1 reduces the band gap of the linker from $4.2 \mathrm{eV}$ to $2.4 \mathrm{eV}$. DFT calculations reveal two spin-dependent gaps of $2.60 \mathrm{eV}$ and $0.48 \mathrm{eV}$ for the alpha and beta spins, respectively, and that the lowest unoccupied crystal orbital for both gaps predominantly resides on the square planar copper atoms. Single-crystal conductivity measurements on TUB1 crystals yield an average electrical conductance of $53.2 \pm 29.5 \mathrm{~S} / \mathrm{m}$. Although the $\mathrm{H}_{8}$-MTPPA linker blocks the extended conjugation in TUB1, we show that the presence of the square planar copper atoms in the inorganic building unit promotes the electrical conductivity.
\end{abstract}

Metal-organic framework (MOF) research has gained significant momentum over the last twenty years. ${ }^{1-3}$ To date, thousands of MOF crystal structures have been deposited into the crystal structure databases with diverse applications in small molecule storage, ${ }^{4-7}$ catalysis, ${ }^{8-10}$ magnetism, ${ }^{11-15}$ conductivity, ${ }^{16,17}$ solar cells, ${ }^{18}$ drug delivery, ${ }^{19,}{ }^{20}$ food chemistry ${ }^{21}$, etc. MOFs provide a synthetically flexible platform ${ }^{22-24}$ and synthesized MOFs may undergo structural optimizations via defect engineering $^{25}$ and post-synthetic modifications. ${ }^{26,27}$ Consequently, MOFs possess greater structural flexibility and a wider range of applications compared to traditional microporous materials such as zeolites, carbon nanotubes ${ }^{28,29}$, and graphene. ${ }^{30-32}$ One of the emerging applications in MOF chemistry is the development of electrically conductive electrode materials for supercapacitor applications. ${ }^{16,33}$ The large surface areas and structural flexibility/diversity of MOFs provide unique advantages for optimizing the conductivity and charge-holding capacities of next-generation supercapacitors. For example, several MOFs are known to possess very high surface areas exceeding 7000 $\mathrm{m}^{2} / \mathrm{g}$ compared to graphene or activated carbon electrodes. ${ }^{34,35}$ However, since current MOF chemistry has evolved around well-separated molecular inorganic building units (IBUs) and well-separated organic struts to increase pore surface areas, ${ }^{24,36}$ this approach inhibits electron-hopping mechanisms for electrical conduction and reduces the magnetic interactions between the metal ions. ${ }^{37}$ This is why conventional MOFs constructed using arylcarboxylic acid linkers are known to be insulators. ${ }^{16,38}$ MOFs containing well-aligned two-dimensional sheets constructed using azolate, ortho-diimine, ortho-dihydroxy, and sulfur-donating linkers have been shown to be highly conductive due to electron-hopping mechanisms (see Ref. ${ }^{16}$ for comprehensive lists of such MOFs). Such linkers are chelators with conserved metal-binding modes, which promote the formation of conductive two-dimensional sheets, e.g., orthodiimine and ortho-dihydroxy MOFs form via the chelation of single square planar metal atoms. As a result, such MOFs generally possess a single type of IBU, which limits their structural diversity and ability to optimize their surface areas and conductivities. ${ }^{16,33,39,40}$

In addition to the two-dimensional conductive MOFs, we have recently shown that arylphosphonic acid linkers with molecular, 
one-, and two-dimensional IBUs can produce electrically conductive three-dimensional MOFs via electron-hopping and extended conjugation mechanisms. In fact, we recently reported the highest single-crystal conductivity for a three-dimensional MOF using arylphosphonic acid linkers. ${ }^{37,41,42}$ Phosphonate MOFs possess extremely rich metal-binding modes compared to any other MOF family in the literature, which give rise to diverse IBUs in one and two dimensions. ${ }^{43-45}$ Phosphonate MOFs with one-dimensional IBUs generally form one-dimensional void channels surrounded by well-stacked aromatic units, ${ }^{46}$ while those with two-dimensional IBUs form pillaredlayered networks. ${ }^{43}$ It is believed that the well-layered aromatic units in such phosphonate MOFs help promote electron hopping and that the continuous arrangement of M-O-P polyhedra in the IBUs extend the conjugation. ${ }^{37,41}$ Moreover, due to their

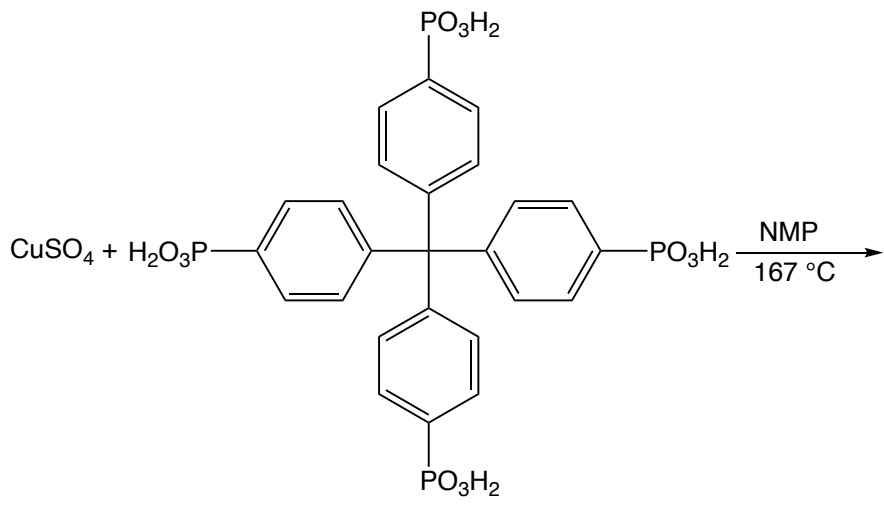

Scheme 1. Solvothermal reaction scheme for the synthesis of TUB1

As seen in Scheme 1, the synthesis involved the reaction between $\mathrm{CuSO}_{4}$ and the $\mathrm{H}_{8}$ MTPPA linker (synthesized according to our previously reported method ${ }^{12}$ ) in a polar aprotic N-methyl-2-pyrrolidone (NMP) solvent at $167^{\circ} \mathrm{C}$ using Teflon-lined $43 \mathrm{ml}$ Parr acid digestion vessels. To ensure that the $\mathrm{H}_{8} \mathrm{MTPPA}$ linker did not fully deprotonate (in order to restrain its metalbinding modes), we adapted our previously employed $\mathrm{pH}$-controlled reaction conditions. ${ }^{12,42,50}$ Using this methodology, we obtained light blue plates of the $\mathrm{Cu}_{3}\left(\mathrm{H}_{5} \text {-MTPPA }\right)_{2}$ MOF (i.e., TUB1) with a tris-deprotonated $\mathrm{H}_{5}-\mathrm{MTPPA}^{3-}$ linker in ca. $2 \%$ average yield and $98 \% \mathrm{H}_{8} \mathrm{MTPPA}$ crystals. Different synthetic conditions with different solvents did not improve the yield as the crystallization of the $\mathrm{H}_{8}$ MTPPA linker was always preferred. Single-crystal x-ray diffraction was used to determine the structure of $\mathrm{Cu}_{3}\left(\mathrm{H}_{5}-\mathrm{MTPPA}\right)_{2}$ (see Figure 1).

As seen in Figure 1, TUB1 is composed of one-dimensional IBUs, which are bridged together by $\mathrm{H}_{5} \mathrm{MTPPA}^{3-}$ linkers. Each IBU is composed of corner-sharing eight-membered $\mathrm{Cu} 1-\mathrm{O}-\mathrm{P}-$ $\mathrm{O}-\mathrm{Cu} 1-\mathrm{O}-\mathrm{P}-\mathrm{O}$ and $\mathrm{Cu} 2-\mathrm{O}-\mathrm{P}-\mathrm{O}-\mathrm{Cu} 2-\mathrm{O}-\mathrm{P}-\mathrm{O}$ rings. Since three of the four phosphonic acid units in the linker are mono-deprotonated, the linker has asymmetric metal-binding modes, viz., the mono-deprotonated units could give rise to ionic exceptionally high thermal and chemical stabilities, phosphonate MOFs could be suitable for applications such as electrodes in supercapacitors for electric vehicles and the storage/supply of energy produced by solar panels and wind turbines. ${ }^{12,47-49} \mathrm{In}$ this work, we report the crystal structure of a newly synthesized phosphonate MOF, termed TUB1, which possesses a unique one-dimensional IBU composed of square planar and distorted trigonal bipyramidal $\mathrm{Cu}(\mathrm{II})$ ions, and a tris deprotonated $\mathrm{H}_{5} \mathrm{MTPPA}^{3-}$ linker. Notably, TUB1 was found to have an indirect band gap of $2.4 \mathrm{eV}$ and an average single-crystal electrical conductivity of $53.2 \pm 29.5 \mathrm{~S} / \mathrm{m}$.

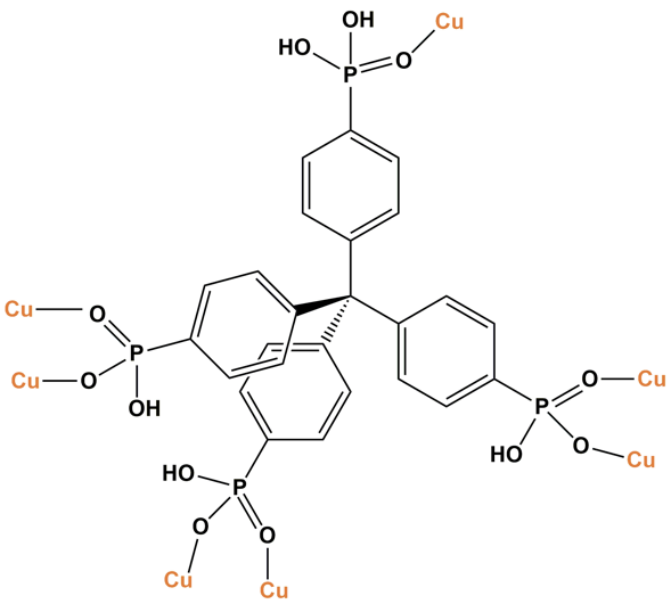

interactions while the fully protonated unit provides coordinate covalent binding. Therefore, TUB1 exhibits two different metal-binding options, in contrast to our previously reported $\mathrm{Co}_{2} \mathrm{H}_{4}$ MTPPA and $\mathrm{Zn}_{2} \mathrm{H}_{4}$ MTPPA MOFs. ${ }^{12,51}$ In particular, the three mono-deprotonated phosphonic acid units are coordinated to square planar and distorted trigonal bipyramidal copper centers (labelled $\mathrm{Cu} 1$ and $\mathrm{Cu} 2$, respectively) via ionic bonding, while the fully protonated unit exclusively generates coordinate covalent bonding between the square planar copper center and the $\mathrm{P}=\mathrm{O}$ bond of the phosphonic acid. (The density functional theory (DFT)-based charge analysis in Table S6 shows that there is high electron delocalization on the deprotonated oxygens, suggesting the possibility of ionic interactions.) To the best of our knowledge, the presence of both trigonal bipyramidal and square planar copper centers in a one-dimensional IBU has not been previously reported for phosphonate MOFs. ${ }^{46}$ The crystal structure of TUB1 indicates the presence of two different types of square- and parallelogram-shaped void channels (see Figure 1). From Grand Canonical Monte Carlo simulations, the BET surface area and Helium-accessible pore volume of TUB1 were estimated to be $766.2 \mathrm{~m}^{2} / \mathrm{g}$ and $0.296 \mathrm{~cm}^{3} / \mathrm{g}$, respectively (see supporting information for details). 

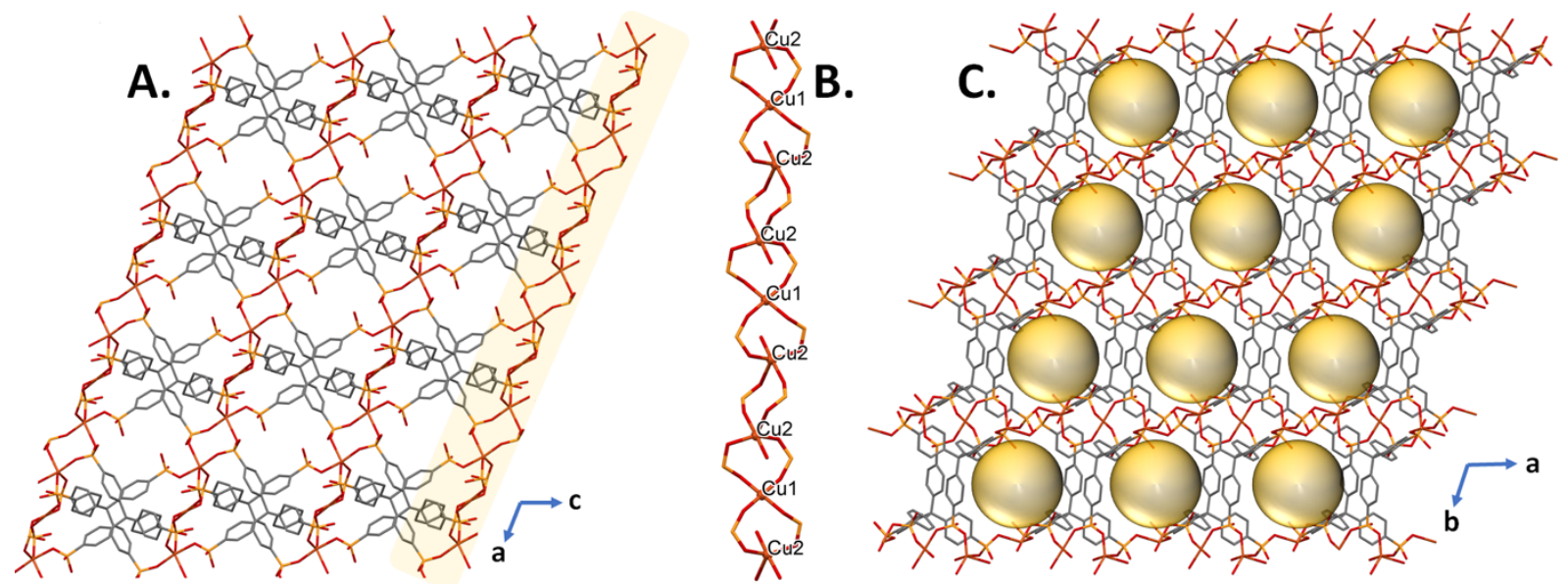

Figure 1. a) View of rectangular void channels (highlighted in yellow) in the ac plane b) Structure of the one-dimensional IBU c) View of parallelogram void channels in the ab plane.

Next, the indirect and direct band gaps of TUB1 were estimated from Tauc plots of the UV-Vis spectrum (see Figure 2), which yielded typical semiconductor jumps at $2.4 \mathrm{eV}$ and $2.7 \mathrm{eV}$, respectively. As seen in Figure 2, the Tauc plots of $\mathrm{H}_{8}$ MTPPA reveal direct and indirect band gaps of ca. $4.2 \mathrm{eV}$, which are considerably wider than those of TUB1 and contain two jumps as opposed to one in the TUB1 plots. This is likely due to the fact that $\mathrm{H}_{5} \mathrm{MTPPA}$ has an insulating $\mathrm{sp}^{3}$ methane core. The lower band gap of TUB1 arises from the formation of one-dimensional IBUs composed of eight-membered Cu1-O-P-O$\mathrm{Cu} 1-\mathrm{O}-\mathrm{P}-\mathrm{O}$ and $\mathrm{Cu} 2-\mathrm{O}-\mathrm{P}-\mathrm{O}-\mathrm{Cu} 2-\mathrm{O}-\mathrm{P}-\mathrm{O}$ rings in the MOF. Such a dramatic change in the Tauc plot after the formation of TUB1 suggests the emergence of an electron hopping mechanism, as the $\mathrm{sp}^{3}$ methane core in $\mathrm{H}_{5} \mathrm{MTPPA}^{3-}$ blocks the extension of conjugation in three dimensions.

We estimated the electrical conductance of single crystals of TUB1 using our previously reported setup (see details in the supporting information). ${ }^{41}$ Our measurements yielded a range of conductivities between ca. 30 and $75 \mathrm{~S} / \mathrm{m}$, with an average of $53.2 \pm 29.5 \mathrm{~S} / \mathrm{m}$, making TUB1 a highly conductive threedimensional MOFs as compared to other MOFs in the literature. ${ }^{16}$ As the TUB1 crystals are very small, it was difficult to orient them between the gold electrodes in our two-point conductivity setup and, thus, it was not possible to obtain directional selectivity for the conductivity measurements. It should also be noted that some crystals broke during the measurements, so that the actual average single-crystal conductivity may be even higher.

A thermal gravimetric analysis of TUB1 was performed to examine its thermal behavior. As seen in Figure S6, at ca. $100^{\circ} \mathrm{C}$, the remaining water molecules evaporate from the structure. NMP starts to leave the pores of TUB 1 at ca. $200^{\circ} \mathrm{C}$ (in accordance with its boiling point at $202^{\circ} \mathrm{C}$ ). The $\mathrm{H}_{5} \mathrm{MTPPA}^{3-}$ organic components start decomposing at ca. $420^{\circ} \mathrm{C}$ and the decomposition pattern remains stable until $850^{\circ} \mathrm{C}$, suggesting the formation of thermally stable phosphide clusters. ${ }^{52}$ This pattern is similar to those of previously reported copper phosphonates, where the organic components start decomposing at ca. $400^{\circ} \mathrm{C}^{50,53}$

To gain a deeper understanding of the origin of the semiconductive behavior in TUB1, we performed DFT calculations of the highest occupied crystal orbital (HOCO)-lowest unoccupied crystal orbital (LUCO) gap, projected density of states (pDOS), $\mathrm{HOCO}$ and LUCO, average partial charges, and band structure.
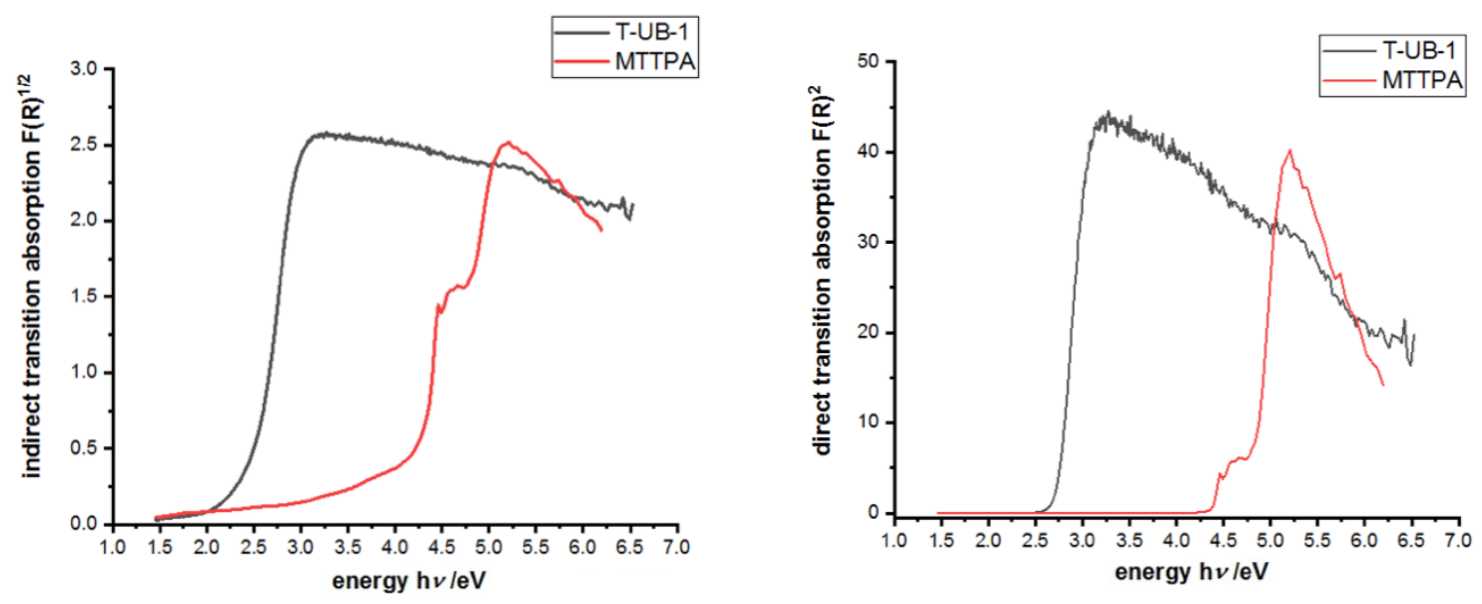

Figure 2. Tauc plots of UV-Vis spectra used to obtain the indirect (left) and direct (right) band gaps of TUB1 and the MTTPA linker. 
The details of our DFT calculations using Slater-type orbitals (STOs) and the HSE06 $6^{54}$ functional may be found in the supporting information. The optimized structures of a $2 \times 2 \times 2$ supercell and a single unit cell of TUB1 are shown in Figure 3, with the spin polarizations of each copper atom indicated on the unit cell. The structural differences between the optimized structure and experimental crystal structure are small (see Table S3). As illustrated in Figure 4, the copper atoms in the unit cell have different coordination environments, with the $\alpha$-copper atoms (i.e., copper atoms with an excess of spin-up electrons) in the trigonal bipyramidal geometry and the $\beta$-copper atom in the square planar geometry.

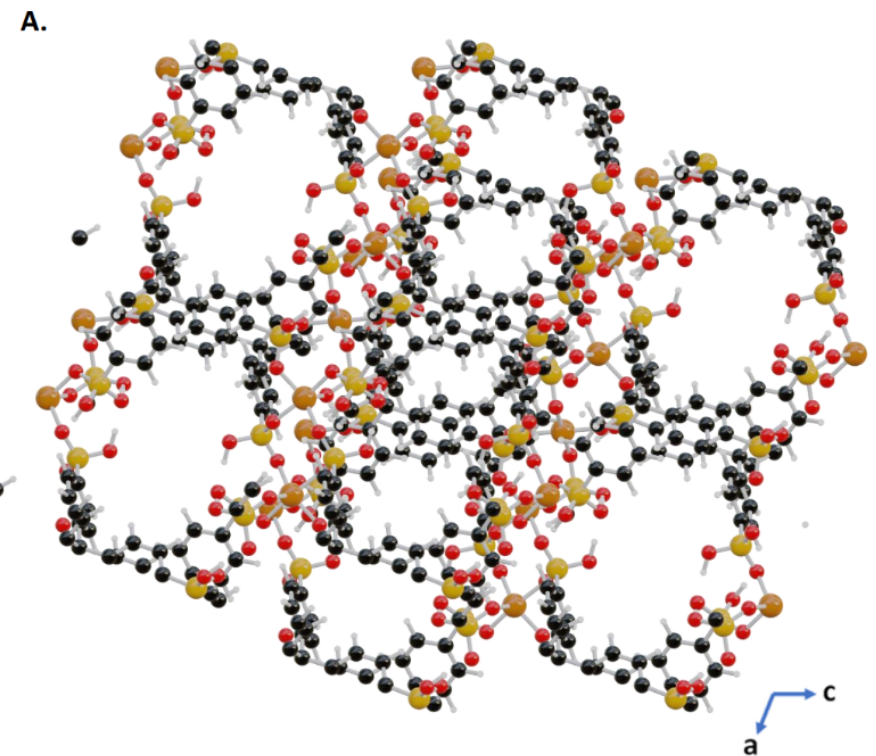

B.

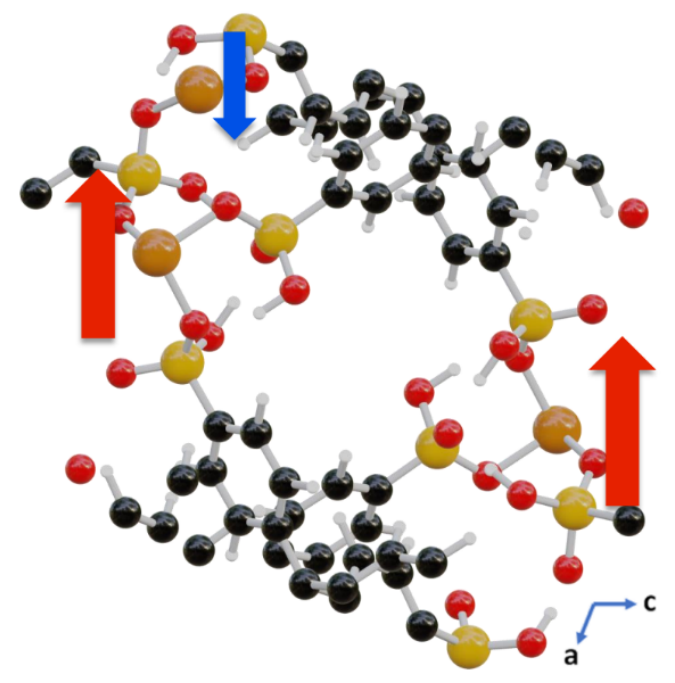

Figure 3. Optimized structure of TUB1. a) A view down the b-axis of the $2 \times 2 \times 2$ supercell. b) A view down the b-axis of the unit cell, with the red (spin-up) and blue (spin-down) arrows indicating the minimum-energy spin configuration of the unpaired electrons on the copper atoms ( $\mathrm{Cu}$ - light brown; $\mathrm{P}$ - yellow; $\mathrm{O}$ - red; $\mathrm{C}$ - black; $\mathrm{H}$ - white).

A.

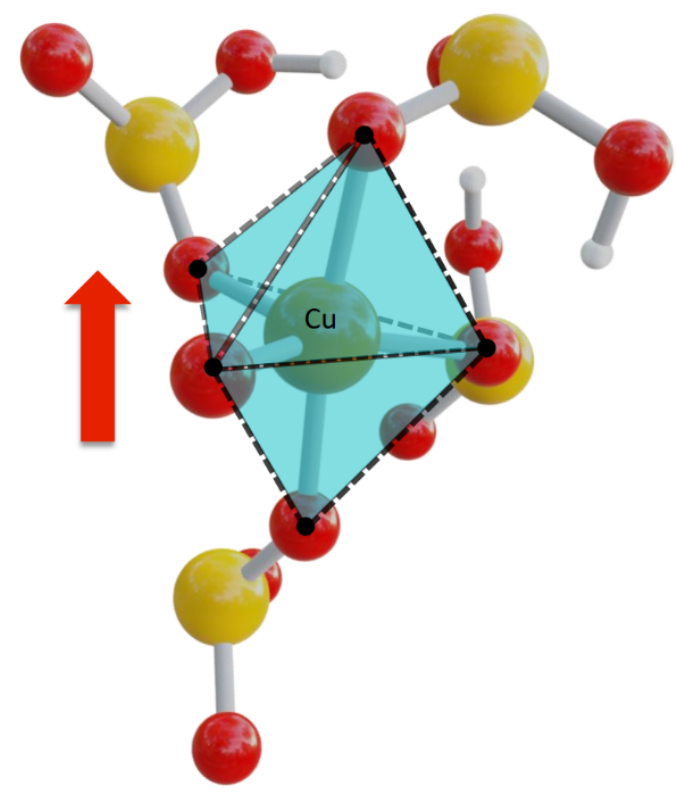

B.

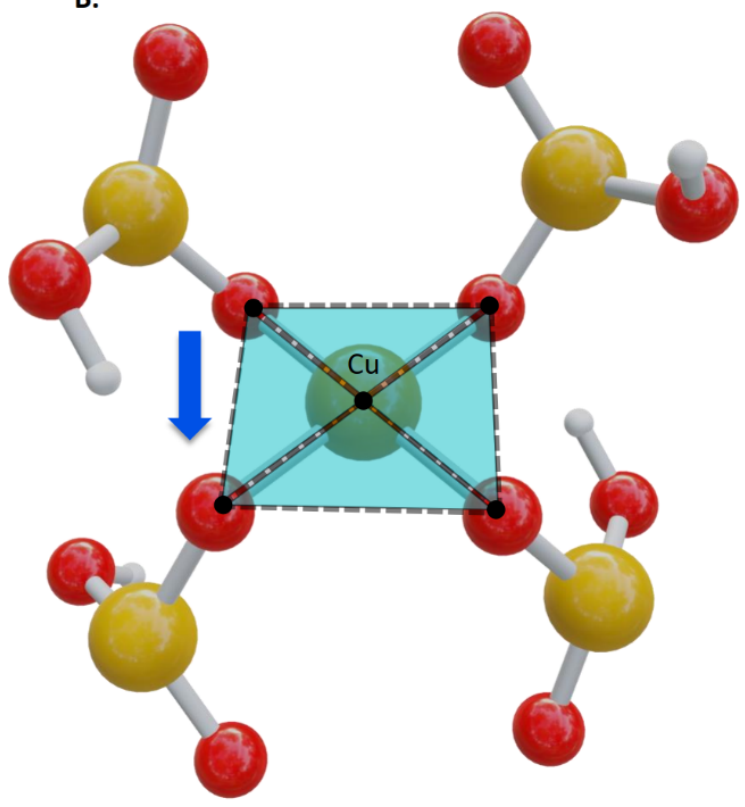

Figure 4. A portion of the TUB1 unit cell, highlighting the two types of copper coordination environments. a) Trigonal bi-pyramidal copper atom coordinated to five oxygen atoms. b) Square planar copper atom coordinated to four oxygen atoms $(\mathrm{Cu}-$ light brown central atom; $\mathrm{P}$ - yellow; $\mathrm{O}$ - red; $\mathrm{H}$ - white).

Next, the pDOS was calculated using the range-separated hybrid functional HSE06, ${ }^{54}$ which is known to yield accurate solid-state HOCO-LUCO gaps. ${ }^{55,56}$ An analysis of the pDOS (shown in Figure 5) reveals a potential electrical conduction mechanism involving two spin-dependent HOCO-LUCO gaps, viz., a spin-up $(\alpha)$ gap of $2.60 \mathrm{eV}$, which is in good agreement 
with the experimental estimates of $2.4 \mathrm{eV}$ (indirect) and $2.7 \mathrm{eV}$ (direct), and a spin-down $(\beta)$ gap of $0.48 \mathrm{eV}$. As seen in the pDOS, the $\beta$-HOCO-LUCO gap, which lies beneath the Fermi energy, is generated by orbitals primarily on the carbon atoms and some on the oxygen and copper atoms. From the $\beta-\mathrm{HOCO}$ and $\beta$-LUCO iso-surfaces in the top panel of Figure 6 , we see that the $\beta$-HOCO is primarily composed of $\pi$-orbitals on the $\mathrm{sp}^{2}$ carbon atoms in half of the phenyl rings down the b-axis. The $\beta$-LUCO is composed of the same phenyl carbon $\pi$-orbitals, as well as $\pi$-orbitals on the oxygen atoms and d-orbitals on the square planar copper atoms (see Figures S3 and S4). From the $\alpha$-HOCO and $\alpha$-LUCO iso-surfaces in the bottom panel of Figure 6 , we see that the $\alpha-\mathrm{HOCO}$ is composed of carbon and oxygen $\pi$-orbitals along the b-axis, while the $\alpha$-LUCO is primarily composed of d-orbitals on the square planar copper atom and $\pi$ orbitals on the oxygen and carbon atoms. The participation of the carbon, oxygen, and square planar copper atoms in both spin-dependent HOCO-LUCO gaps suggests that they are integral in facilitating electrical conduction in TUB1.

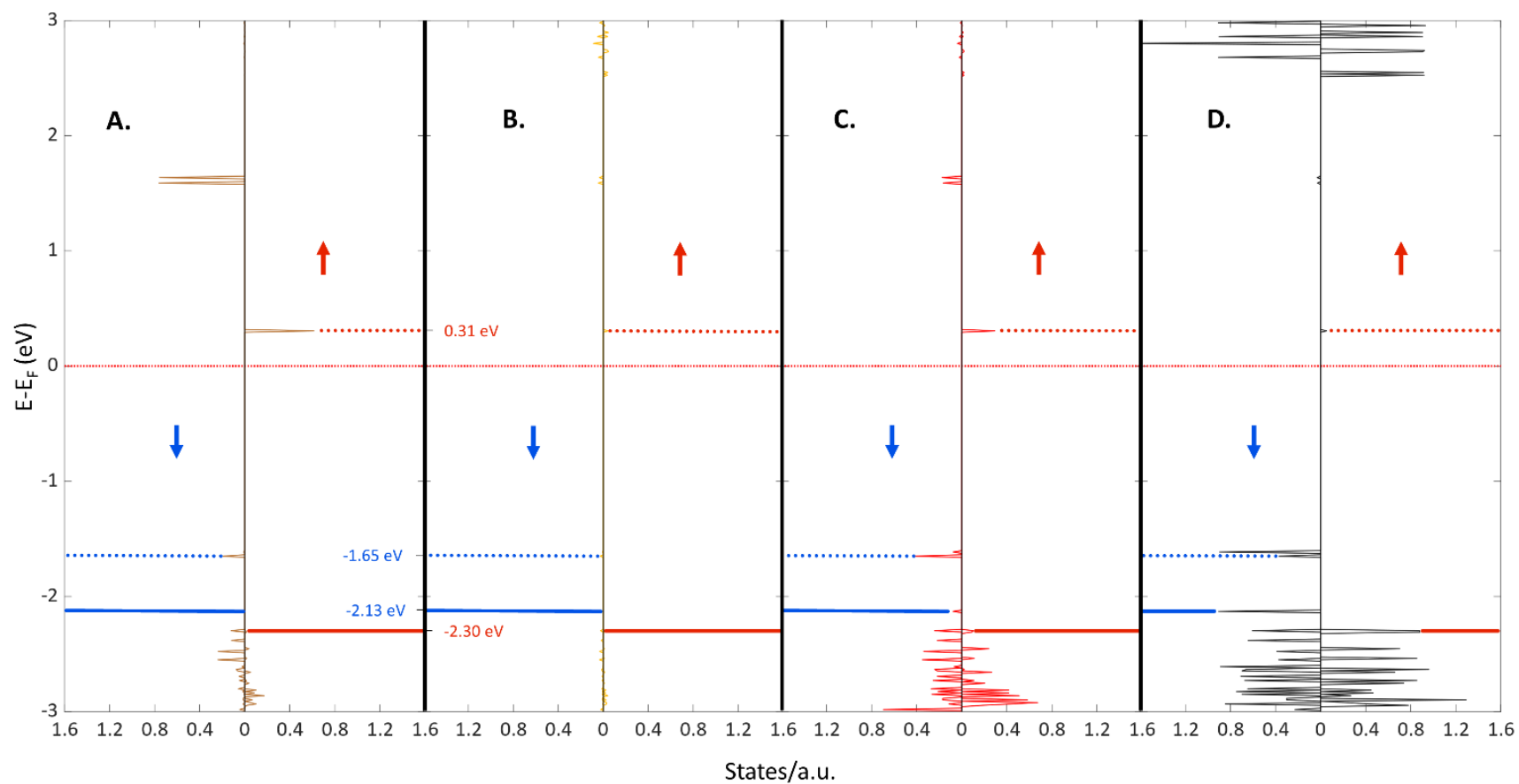

Figure 5. Spin-up (red arrow) and spin-down (blue arrow) projected density of states for TUB1: (A) Copper, (B) Phosphorous, (C) Oxygen, (D) Carbon. The solid red and blue lines indicate the $\alpha$ - and $\beta$-HOCO energy levels, respectively. The dotted red and blue lines indicate the $\alpha$ - and $\beta$-LUCO energy levels, respectively. The blue numbers in panel A indicate the energies of the $\beta$-HOCO and $\beta$-LUCO, while the red numbers in panel B indicate the energies of the $\alpha$-HOCO and $\alpha$-LUCO.

The band structure of TUB1 is shown in Figure S5. As can be seen, there are $120 \mathrm{meV}$ dispersions in the $\beta$-LUCO band along the $\mathrm{X}-\Gamma, \Gamma-\mathrm{Y}, \mathrm{L}-\Gamma, \Gamma-\mathrm{Z}, \mathrm{N}-\Gamma, \Gamma-\mathrm{M}$, and $\mathrm{R}-\Gamma$ paths in $\mathrm{k}$-space. This points to higher electron mobility in several directions (compared to typical semiconducting MOFs, which have linear bands or bands with dispersions of less than $50 \mathrm{meV}^{16,57}$ ), and thereby suggests that the electrical conductivity of TUB1 is not directionally dependent. 

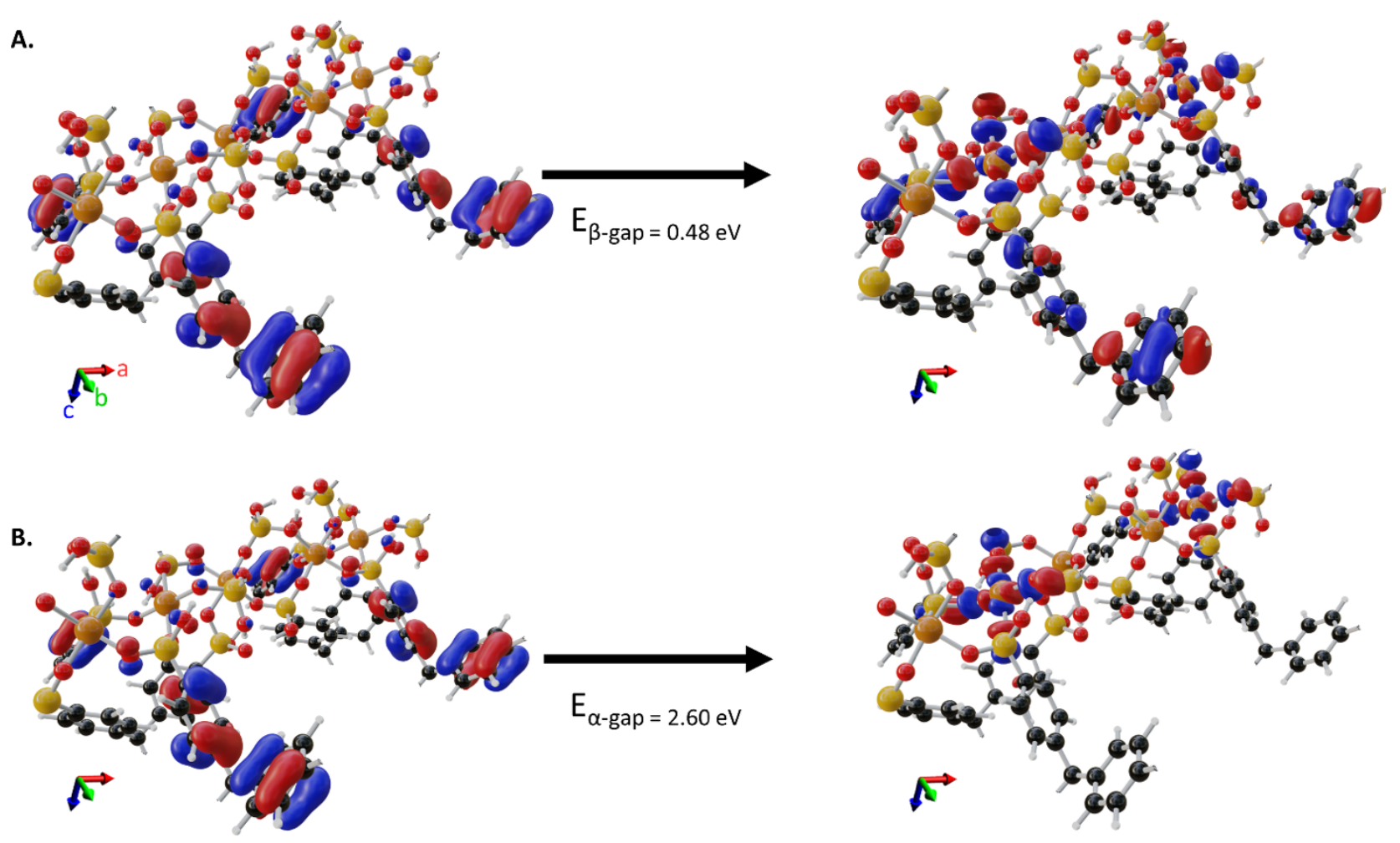

Figure 6. HOCO and LUCO iso-density surfaces, corresponding to a density of 1 electron per $0.03 \AA^{3}$. A) $\beta$-spin HOCO-LUCO gap. B) $\alpha$ spin HOCO-LUCO gap. For clarity, only a portion of the unit cell is shown ( $\mathrm{Cu}$ - light brown; $\mathrm{P}$ - yellow; $\mathrm{O}-\mathrm{red} ; \mathrm{C}-\mathrm{black}$; $\mathrm{H}-$ white).

In summary, we have reported on the synthesis and electronic properties of the semiconductive three-dimensional $\mathrm{MOF}$ TUB1, which possesses a unique one-dimensional IBU composed of corner-sharing eight-membered Cul-O-P-O-Cu1-O$\mathrm{P}-\mathrm{O}$ and $\mathrm{Cu} 2-\mathrm{O}-\mathrm{P}-\mathrm{O}-\mathrm{Cu} 2-\mathrm{O}-\mathrm{P}-\mathrm{O}$ rings containing square planar and distorted trigonal bipyramidal copper centers. TUB1 was found to have a BET surface area of $766.2 \mathrm{~m}^{2} / \mathrm{g}$ and Heliumaccessible pore volume of $0.296 \mathrm{~cm}^{3} / \mathrm{g}$ (as predicted by Monte Carlo simulations), indirect band gap of $2.4 \mathrm{eV}$, and average single-crystal electrical conductance of $53.2 \pm 29.5 \mathrm{~S} / \mathrm{m}$. Our DFT calculations confirm the experimental structure, yield spin-dependent HOCO-LUCO gaps of $2.60 \mathrm{eV}(\alpha)$ and $0.48 \mathrm{eV}$ $(\beta)$, suggest a role of the square planar copper centers in reducing the HOCO-LUCO gap, and point to above-normal non-directional electron mobility. The uniqueness of TUB1's IBU was made possible by the structural diversity afforded by phosphonate metal-binding groups. Such metal phosphonate IBUs may be used to construct highly conductive MOFs with polyaromatic cores for use in next-generation supercapacitors.

\section{ASSOCIATED CONTENT}

Supporting Information. Details of TUB1 synthesis, grand canonical Monte Carlo simulation details, DFT simulation details, thermogravimetric analysis profiles for TUB1 and MTTPA, X-ray and structure refinement data. Details of conductivity measurements.

\section{AUTHOR INFORMATION}

\section{Corresponding Author}

* Correspondence to: yuecesan@tu-berlin.de, gabriel.hanna@ualberta.ca, j.beckmann@uni-bremen.de

\section{Author Contributions}

C.A.P. performed all DFT calculations, analyzed the DFT results, generated the corresponding figures/tables, co-wrote the corresponding parts of the manuscript, assisted with the editing process, and formatted the manuscript. A.C. and P.T. synthesized the compounds. P.T. contributed to the crystal structure refinement. A.C. purified the crystals, performed the TGA and experimental band-gap measurements, and prepared the samples for single crystal diffraction and conductivity measurements. F-J.S. performed the single-crystal electrical conductivity measurements. Y.Z. performed the refinement of the crystal structure, and prepared the crystallographic tables and figures. K.B.Y. performed the surface area calculations and wrote the corresponding text. A.O.Y. supervised K.B.Y.'s work and revised the corresponding text. J.B. supervised the work and contributed to the manuscript. G.H. supervised the DFT calculations, assisted with the analysis of the DFT results, co-wrote the corresponding parts of the manuscript, performed extensive critical revisions of the entire manuscript, and edited the entire manuscript. G.Y. created the hypothesis, supervised the project, and co-wrote/revised the non-computational parts of the manuscript. All authors have given approval to the final version of the manuscript.

\section{Funding Sources}

G.Y. would like to thank the DFG for funding his work with grant number DFG YU 267/2-1 and J.B. would like to thank the DFG for funding his work with grant number BE 3716/9-1. G.H. acknowledges funding from the Natural Sciences and Engineering Research Council of Canada (NSERC).

\section{ACKNOWLEDGMENT}

The DFT calculations were enabled by support provided by WestGrid (www.westgrid.ca) and Compute Canada (www.computecanada.ca). 


\section{ABBREVIATIONS}

MOF, metal-organic framework; $\mathrm{H}_{8}$-MTPPA, methane tetra- $p$ phenylphosphonic acid; IBU, inorganic building unit; NMP, N-methyl-2-pyrrolidone; TUB1, Technische Universität Berlin 1; DFT, density functional theory; HOCO, highest occupied crystal orbital; LUCO, lowest unoccupied crystal orbital; $\mathrm{pDOS}$, projected density of states; STO, Slater-type orbital; HSE06, Heyd-ScuseriaErnzerhof 06.

\section{REFERENCES}

1. Kalmutzki, M. J.; Hanikel, N.; Yaghi, O. M., Secondary building units as the turning point in the development of the reticular chemistry of MOFs. Sci Adv 2018, 4,10.

2. Rowsell, J. L. C.; Yaghi, O. M., Metal-Organic Frameworks: A New Class of Porous Materials. Micropor. Mesopor. Mater. 2004, 73, 3 .

3. Evans, J. D.; Garai, B.; Reinsch, H.; Li, W.; Dissegna, S.; Bon, V.; Senkovska, I.; Fischer, R. A.; Kaskel, S.; Janiak, C.; Stock, N.; Volkmer, D., Metal-organic frameworks in Germany: From synthesis to function. Coord. Chem. Rev. 2019, 380, 378-418.

4. Moghadam, P. Z.; Li, A.; Liu, X. W.; Bueno-Perez, R.; Wang, S. D.; Wiggin, S. B.; Wood, P. A.; Fairen-Jimenez, D., Targeted classification of metal-organic frameworks in the Cambridge structural database (CSD). Chem. Sci. 2020, 11 (32), 8373.

5. Li, A.; Bueno-Perez, R.; Wiggin, S.; Fairen-Jimenez, D., Enabling efficient exploration of metal-organic frameworks in the Cambridge Structural Database. CrystEngComm. 2020, 22, 7152.

6. Férey, G.; Serre, C.; Devic, T.; Maurin, G.; Jobic, H.; Llewellyn, P. L.; De Weireld, G.; Vimont, A.; Daturi, M.; Chang, J.S., Why hybrid porous solids capture greenhouse gases? Chem. Soc. Rev. 2011, 40 (2), 550-562.

7. Schneemann, A.; Bon, V.; Schwedler, I.; Senkovska, I.; Kaskel, S.; Fischer, R. A., Flexible metal-organic frameworks. Chem. Soc. Rev. 2014, 43 (16), 6062-96.

8. Yang, D.; Gates, B. C., Catalysis by Metal Organic Frameworks: Perspective and Suggestions for Future Research. ACS Catal. 2019, 9, 1779.

9. Corma, A.; García, H.; Llabrés i Xamena, F. X., Engineering Metal Organic Frameworks for Heterogeneous Catalysis. Chem. Rev. 2010, 110, 4606.

10. Ma, L.; Falkowski, J. M.; Abney, C.; Lin, W., A Series of Isoreticular Chiral Metal-Organic Frameworks as a Tunable Platform for Asymmetric Catalysis. Nat. Chem. 2010, 2, 838.

11. Riou, D.; Belier, F.; Serre, C.; Noguès, M.; Vichard, D.; Férey, G., Hybrid Open-Frameworks: Hydrothermal Synthesis, Structure Determinations and Magnetic Properties of MIL-29, Two Copper Diphosphonates $\left(\mathrm{Cu}^{\mathrm{II}}\left(\mathrm{H}_{2} \mathrm{O}\right)\right)_{2}\left\{\mathrm{O}_{3} \mathrm{P}-\mathrm{X}-\mathrm{PO}_{3}\right\}$ with $\mathrm{X}=\mathrm{C}_{2} \mathrm{H}_{4}$, $\mathrm{CH}_{2}-\mathrm{C}_{6} \mathrm{H}_{4}-\mathrm{CH}_{2}$. Int. J. Inorg. Mater. 2000, 2, 29.

12. Zorlu, Y.; Erbahar, D.; Çetinkaya, A.; Bulut, A.; Erkal, T S.; Yazaydin, A. O.; Beckmann, J.; Yücesan, G., A cobalt arylphosphonate MOF - superior stability, sorption and magnetism. Chem. Commun. (Camb) 2019, 55 (21), 3053-3056.

13. Ouellette, W.; Prosvirin, A. V.; Whitenack, K.; Dunbar, K. R.; Zubieta, J., A Thermally and Hydrolytically Stable Microporous Framework Exhibiting Single-Chain Magnetism: Structure and Properties of $\left[\mathrm{Co}_{2}\left(\mathrm{H}_{0.67} \mathrm{bdt}\right)_{3}\right] \cdot 20 \mathrm{H}_{2} \mathrm{O}$. Angew. Chem., Int. Ed. 2009, 48, 2140.

14. Wang, Z.; Hu, K.; Gao, S.; Kobayashi, H., Formate-Based Magnetic Metal-Organic Frameworks Templated by Protonated Amines. Adv. Mater. 2010, 22, 1526.

15. Thorarinsdottir, A. E.; Harris, T. D., Metal-Organic Framework Magnets. Chem. Rev. 2020, 120 (16), 8716-8789.

16. Xie, L. S.; Skorupskii, G.; Dincă, M., Electrically Conductive Metal-Organic Frameworks. Chem. Rev. 2020, 120 (16), 8536-8580.

17. Sun, L.; Campbell, M. G.; Dincă, M., Electrically Conductive Porous Metal-Organic Frameworks. Angew. Chem., Int Ed. Engl 2016, 55 (11), 3566-79.
18. Chueh, C.-C.; Chen, C.-I.; Su, Y.-A.; Konnerth, H.; Gu, Y.-J.; Kung, C.-W.; Wu, K. C. W., Harnessing MOF materials in photovoltaic devices: recent advances, challenges, and perspectives. $J$. Mater. Chem. A 2019, 7 (29), 17079-17095.

19. Rojas, S.; Arenas-Vivo, A.; Horcajada, P., Metal-organic frameworks: A novel platform for combined advanced therapies. Coord. Chem. Rev. 2019, 388, 202-226.

20. Horcajada, P.; Chalati, T.; Serre, C.; Gillet, B.; Sebrie, C.; Baati, T.; Eubank, J. F.; Heurtaux, D.; Clayette, P.; Kreuz, C.; Chang, J.-S.; Hwang, Y. K.; Marsaud, V.; Bories, P.-N.; Cynober, L.; Gil, S.; Férey, G.; Couvreur, P.; Gref, R., Porous metal-organicframework nanoscale carriers as a potential platform for drug delivery and imaging. Nat. Mater. 2010, 9 (2), 172-178.

21. Manousi, N.; Zachariadis, G. A.; Deliyanni, E. A.; Samanidou, V. F., Applications of Metal-Organic Frameworks in Food Sample Preparation. Molecules 2018, 23 (11).

22. Furukawa, H.; Cordova, K. E.; O’Keeffe, M.; Yaghi, O. M., The chemistry and applications of metal-organic frameworks. Science 2013, 341 (6149), 1230444.

23. Zhou, H. C.; Long, J. R.; Yaghi, O. M., Introduction to metal-organic frameworks. Chem. Rev. 2012, 112 (2), 673-4.

24. Yaghi, O. M.; Kalmutzki, M. J.; Diercks, C. S. Introduction to reticular chemistry: metal-organic frameworks and covalent organic frameworks. Weinheim: Wiley-VCH, 2019.

25. Taddei, M., When defects turn into virtues: The curious case of zirconium-based metal-organic frameworks. Coord. Chem. Rev. 2017, 343, 1-24.

26. Kim, M.; Cahill, J. F.; Su, Y.; Prather, K. A.; Cohen, S. M., Postsynthetic Ligand Exchange as a Route to Functionalization of 'Inert' Metal-Organic Frameworks. Chem. Sci. 2012, 3, 126

27. Cohen, S. M., The Postsynthetic Renaissance in Porous Solids. J. Am. Chem. Soc. 2017, 139, 2855.

28. Scott, L. T.; Jackson, E. A.; Zhang, Q. Y.; Steinberg, B. D.; Bancu, M.; Li, B., A Short, Rigid, Structurally Pure Carbon Nanotube by Stepwise Chemical Synthesis. J. Am. Chem. Soc. 2012 , 134, 107.

29. Xiao, B.; Wheatley, P. S.; Morris, R. E.; Xu, R.; Gao, Z.; Chen, J.; Yan, W., From Zeolites to Porous MOF Materials-The 40th Anniversary of International Zeolite Conference. 2007; p 902.

30. Jiang, L.; Fan, Z., Design of Advanced Porous Graphene Materials: From Graphene Nanomesh to 3d Architectures. Nanoscale 2014, 6, 1922.

31. Allen, M. J.; Tung, V. C.; Kaner, R. B., Honeycomb Carbon: A Review of Graphene. Chem. Rev. 2010, 110, 132.

32. Clancy, A. J.; Au, H.; Rubio, N.; Coulter, G. O.; Shaffer, M. S. P., Understanding and controlling the covalent functionalisation of graphene. Dalton Trans. 2020, 49 (30), 10308-10318.

33. Sheberla, D.; Bachman, J. C.; Elias, J. S.; Sun, C. J.; ShaoHorn, Y.; Dinca, M., Conductive MOF Electrodes for Stable Supercapacitors with High Areal Capacitance. Nat. Mater. 2017, 16, 220

34. Farha, O. K.; Eryazici, I.; Jeong, N. C.; Hauser, B. G.; Wilmer, C. E.; Sarjeant, A. A.; Snurr, R. Q.; Nguyen, S. T.; Yazaydın, A.; Hupp, J. T., Metal-organic framework materials with ultrahigh surface areas: is the sky the limit? J. Am. Chem. Soc. 2012, 134 (36), 15016-21.

35. Hönicke, I. M.; Senkovska, I.; Bon, V.; Baburin, I. A Bönisch, N.; Raschke, S.; Evans, J. D.; Kaskel, S., Balancing Mechanical Stability and Ultrahigh Porosity in Crystalline Framework Materials. Angew. Chem., Int. Ed. Engl. 2018, 57 (42), 13780-13783.

36. Yaghi, O. M.; O’Keeffe, M.; Ockwig, N. W.; Chae, H. K.; Eddaoudi, M.; Kim, J., Reticular synthesis and the design of new materials. Nature 2003, 423, 705.

37. Siemensmeyer, K.; Peeples, C. A.; Tholen, P.; Schmitt, F. J.; Çoşut, B.; Hanna, G.; Yücesan, G., Phosphonate Metal-Organic Frameworks: A Novel Family of Semiconductors. Adv. Mater. 2020, 32 (24), 202000474.

38. Taddei, M.; Schukraft, G. M.; Warwick, M. E. A.; Tiana, D.; McPherson, M. J.; Jones, D. R.; Petit, C., Band gap modulation in zirconium-based metal-organic frameworks by defect engineering. $J$. Mater. Chem. A 2019, 7 (41), 23781-23786. 
39. Campbell, M. G.; Sheberla, D.; Liu, S. F.; Swager, T. M.; Dincă, M., Cu3(Hexaiminotriphenylene)2: An Electrically Conductive 2D Metal-Organic Framework for Chemiresistive Sensing. Angew. Chem., Int. Ed. 2015, 54, 4349.

40. Day, R. W.; Bediako, D. K.; Rezaee, M.; Parent, L. R.; Skorupskii, G.; Arguilla, M. Q.; Hendon, C. H.; Stassen, I.; Gianneschi, N. C.; Kim, P.; Dincă, M., Single Crystals of Electrically Conductive Two-Dimensional Metal-Organic Frameworks: Structural and Electrical Transport Properties. ACS Cent. Sci. 2019, 5 (12), 19591964.

41. Peeples, C. A.; Kober, D.; Schmitt, F.-J.; Tholen, P.; Siemensmeyer, K.; Halldorson, Q.; Çoşut, B.; Gurlo, A.; Yazaydin, A. O.; Hanna, G.; Yücesan, G., A 3D Cu-Naphthalene-Phosphonate Metal-Organic Framework with Ultra-High Electrical Conductivity. Adv. Funct. Mater. 2021, 31, 2007294.

42. Yunus, Z.; Patrik, T.; Mehmet Menaf, A.; Ceyda, B.; Gabriel, H.; A. Ozgur, Y.; Ozgur, Y.; Gündoğ, Y., High Electrical Conductivity in Three-Dimensional Porphyrin-Phosphonate Metal Organic-Frameworks.

2021, https://doi.org/10.26434/chemrxiv.13653050.v1

43. Yücesan, G.; Zorlu, Y.; Stricker, M.; Beckmann, J., Metalorganic solids derived from arylphosphonic acids. Coord. Chem. Rev. 2018, 369, 105-122.

44. Coxall, R. A.; Harris, S. G.; Henderson, D. K.; Parsons, S.; Tasker, P. A.; Winpenny, R. E. P., Inter-ligand reactions: in situ formation of new polydentate ligands. J. Chem. Soc., Dalton Trans. 2000, (14), 2349-2356.

45. Sahoo, D.; Suriyanarayanan, R.; Chandrasekhar, V., Di-, triand tetranuclear molecular vanadium phosphonates: a chloride encapsulated tetranuclear bowl. Dalton Trans. 2014, 43 (28), 1089810909.

46. Tholen, P.; Zorlu, Y.; Beckmann, J.; Yücesan, G., Probing Isoreticular Expansions in Phosphonate MOFs and their Applications. Eur. J. Inorg. Chem. 2020, 2020 (17), 1542-1554.

47. Zhu, Y.-P.; Yin, J.; Abou-Hamad, E.; Liu, X.; Chen, W.; Yao, T.; Mohammed, O. F.; Alshareef, H. N., Highly Stable Phosphonate-Based MOFs with Engineered Bandgaps for Efficient Photocatalytic Hydrogen Production. Adv. Mater. 2020, 32 (16), 1906368.
48. Gao, C. Y.; Ai, J.; Tian, H. R.; Wu, D.; Sun, Z. M., An ultrastable zirconium-phosphonate framework as bifunctional catalyst for highly active CO. Chem. Commun. (Camb) 2017, 53 (7), 12931296.

49. Zheng, T.; Yang, Z.; Gui, D.; Liu, Z.; Wang, X.; Dai, X.; Liu, S.; Zhang, L.; Gao, Y.; Chen, L.; Sheng, D.; Wang, Y.; Diwu, J.; Wang, J.; Zhou, R.; Chai, Z.; Albrecht-Schmitt, T. E.; Wang, S., Overcoming the crystallization and designability issues in the ultrastable zirconium phosphonate framework system. Nat. Commun. $\mathbf{2 0 1 7}, 8,15369$

50. Ayhan, M. M.; Bayraktar, C.; Yu, K. B.; Hanna, G.; Yazaydin, A. O.; Zorlu, Y.; Yücesan, G., A Nanotubular MetalOrganic Framework with a Narrow Bandgap from Extended Conjugation**. Eur. J. Inorg. Chem. 2020, 26 (65), 14813-14816.

51. Schütrumpf, A.; Bulut, A.; Hermer, N.; Zorlu, Y.; Kirpi, E.; Stock, N.; Yazaydın, A. Ö.; Yücesan, G.; Beckmann, J., From Tetrahedral Tetraphosphonic Acids E[p-C6H4P $(\mathrm{O})(\mathrm{OH}) 2] 4(\mathrm{E}=\mathrm{C}, \mathrm{Si})$ to Porous $\mathrm{Cu}-$ and $\mathrm{Zn}-\mathrm{MOF}$ with Large Surface Areas. ChemistrySelect 2017, 2 (10), 3035-3038.

52. Zhang, R.; Russo, P. A.; Feist, M.; Amsalem, P.; Koch, N.; Pinna, N., Synthesis of Nickel Phosphide Electrocatalysts from Hybrid Metal Phosphonates. ACS Appl. Mater. Interfaces 2017, 9 (16), 14013-14022.

53. Enakieva, Y. Y.; Sinelshchikova, A. A.; Grigoriev, M. S.; Chernyshev, V. V.; Kovalenko, K. A.; Stenina, I. A.; Yaroslavtsev, A. B.; Gorbunova, Y. G.; Tsivadze, A. Y., Highly Proton-Conductive Zinc Metal-Organic Framework Based On Nickel(II) Porphyrinylphosphonate. Chem. Eur. J. 2019, 25 (45), 10552-10556.

54. Heyd, J., Scuseria, G. E. \& Ernzerhof, M. Erratum: Hybrid functionals based on a screened Coulomb potential. J.Chem. Phys. 2006, 124, 219906.

55. Garza, A. J. \& Scuseria, G. E. Predicting Band Gaps with Hybrid Density Functionals. J. Phys. Chem. Lett. 2016, 7, 4165-4170.

56. Perdew, J. P. et al. Understanding band gaps of solids in generalized Kohn-Sham theory. Proc. Natl. Acad. Sci. U. S. A. 2017, 114, 2801-2806.

57. A. Pathak, J. W. Shen, M. Usman, L. F. Wei, S. Mendiratta, Y. S. Chang, B. Sainbileg, C. M. Ngue, R. S. Chen, M. Hayashi, T. T. Luo, F. R. Chen, K. H. Chen, T. W. Tseng, L. C. Chen and K. L. Lu, Nat. Commun. 2019, 10, 1-7. 